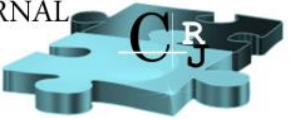

\title{
Failures and changes in the facial emotion recognition in patients with schizophrenia, siblings, and control subjects.
}

\section{Saracco-Alvarez Ricardo a*, Fresán Ana b, Escamilla-Orozco Raúl a}

a Clínica de Esquizofrenia. Instituto Nacional de Psiquiatría Ramón de la Fuente, Mexico City, Mexico.

b Subdirección de Investigaciones Clínicas, Instituto Nacional de Psiquiatría Ramón de la Fuente, Mexico City, Mexico

*Corresponding author:

Saracco-Alvarez Ricardo.

Clínica de Esquizofrenia. Instituto Nacional de Psiquiatría Ramón de la Fuente

Calz. México-Xochimilco No 101. Tlalpan. CP 14370

Mexico City. Mexico.

Tel. + 525541605257 .

Email.dr_saracco@yahoo.com.mx

All authors declare they have no conflicts of interest.

\begin{abstract}
Background: Facial affect recognition is the ability of all individuals to recognize basic forms of affective expression reflected on people's faces. These expressions are happiness, sadness, fear, disgust, surprise, anger, and the absence of emotion, also called neutral expression. Patients with schizophrenia present difficulty in recognizing these expressions in themselves and/or in other people.
\end{abstract}

Objective: The objective was to determinate which emotions were confused and for what other emotion they were taken for (misattribution).

Method: We included three groups: 34 schizophrenic patients, 34 siblings, and 34 control subjects. All patients attend the schizophrenia clinic, their siblings were those closest in age and gender, and subjects without mental illness were paired by age and gender. We used SCID-I and SCL-90 scales to discard mental illness in siblings and controls. PANSS, CDSS, and CGI were used to measure the severity of the disease in schizophrenic patients. We used the Pictures of Facial Affect developed by Ekman (1976), to evaluate facial affect recognition.

Results: Across all groups, the least recognized emotion was fear; in the patients and siblings groups, the most recognized emotion was surprise. In the patient group happiness was mistaken for the neutral face in $13 \%$. The patients mistook anger for neutral face in 5.6\%, fear in 5.2\%, surprise in 5.0\%, and disgust in $4.9 \%$. Neutral face: only the patients group mistook the neutral face for sadness in $4.6 \%$. Fear was the least recognized emotion; the patient group mistook it for surprise in $42.6 \%$ and anger in $6.9 \%$. The siblings mistook it for surprise in $41.3 \%$, and the control group also for surprise in $25.4 \%$. Disgust: It was mistaken for anger by patients in $25.6 \%$, siblings in $23.3 \%$, and control subjects in $11.5 \%$. Sadness: it was mistaken for fear in $15.6 \%$, and for neutral faces in $10.9 \%$ in the patients group. In the siblings group the sadness was mistaken for fear in $14.1 \%$, and the controls group sadness was mistaken for fear in $11.1 \%$. 
Discussion: patients with schizophrenia recognize facial emotion expressions less well than siblings and the control group. The differences in the recognition of emotions in previous studies reported a poor recognition of fear and sadness.

In our study, we found in all groups that fear was mistaken for surprise. The patient group showed differences in relation to other groups, but the sibling group was closer to the patient group than to controls. The control group had a lesser degree of failure in recognizing emotion. This supports the presence of basic cognitive failures in patients and their siblings, reinforcing the fact that facial affect recognition could be part of a cognitive endophenotype.

Keywords: Facial emotion; affect recognition; schizophrenia; endophenotype.

\section{Introduction}

One of the main dysfunctions caused by schizophrenia occurs in the social area, where patients are socially isolated or show inappropriate social behaviors. It could be considered that these dysfunctions are related to an inadequate processing of social information in patients with schizophrenia. This process of social information, mainly known as social cognition, refers to the way people encode, store, retrieve, and apply information in social situations.

A key feature to social cognition is emotion recognition. Social cognition is part of the cognitive spectrum in humans and primates. It is the study of how people process social information, especially its encoding, storage, retrieval, and application on social situations (Cacioppo et al., 2000). Facial recognition is one of the most important skills for social interaction and communication. It is the ability that all humans and animals use to recognize the affective expression on the faces of members of the same species and/or in other species (Hall et al., 2004: Rusell, 1994). The basic affective expressions of facial recognition are: happiness, sadness, fear, disgust, surprise, anger, and the absence of emotion or neutral emotion. These emotions are universal and accepted by all cultures. Some trials show that these emotions are essential in social relationships and, if someone cannot recognize an emotion, this could lead to major problems in their social relationships (Ekman, 1994; Elfenbein and Ambady, 2002; Brekke et al., 2005).

These problems have been frequently considered in patients with schizophrenia. This is one issue believed to isolate people, because they cannot correctly recognize the expressions resulting in diminished ability to relate to others. Poor facial recognition is more frequent when recognizing negative emotions, such as fear, sadness, and anger (Gard et al., 2011).

These outcomes are present on a lesser degree in siblings of schizophrenic patients, as well as in controls subjects. This phenomenon has been considered part of the cognitive endophenotype. Endophenotypes are alterations in the biochemical, neurophysiological, neuroanatomical, and cognitive functions. These alterations are determined by genetic and environmental factors, and they are related to physiopathological processes that increase the vulnerability to developing any given disease. These endophenotypes are the variations found in patients, patient's siblings, and control subjects that could increase the risk of developing a mental disorder (Gottesman and Gould, 2003).

When used diffusor tensor imaging studies examining schizophrenia have found lower levels of tissue organization, manifested as lower fractional anisotropy values in schizophrenia patients and in individuals at high risk for developing psychosis, when compared to controls (Camchong, et al., 2011). The degree to which white matter disorganization in medial frontal regions could be a biological marked or endophenotype 
associated with schizophrenia, and Camchong, et al (2009) showed reduced white matter integrity in the patients overlapped regions that their found to be highly correlated between monozygotic twin pairs, suggesting that schizophrenia-associated reduced white matter integrity in this region may be heritable trait.

The aim of this study was to determine which emotions were misrecognized and for which one they were mistaken (misattribution) in three groups of subjects: a) Schizophrenic patients, b) patients' siblings and, c) control subjects.

\section{Methods-Subjects section.}

\subsection{Subjects}

We included 102 subjects: 34 schizophrenic patients, 34 siblings, and 34 controls (non-psychotic subjects). We invited the patients' siblings of the same gender, and closer in age to participate in the study. The control group was paired according to gender and age. This trial was approved by the Local Ethics Committee, and we obtained informed written consent. Demographic data was obtained by personal interview with the subjects.

\subsection{Assessment procedures in patients group}

The group of patients with schizophrenia was recruited from the outpatient admission ward at the National Institute of Psychiatry (Mexico City), according to DSM-IV-TR diagnostic criteria. Subjects had no alcohol, no drug abuse (with the exception of nicotine and/or caffeine), and no neurological comorbidities when included. Diagnoses were based in clinical interviews by two psychiatrics with 10 years of experience in schizophrenia patients, and diagnoses were confirmed by the Structured Clinical Interview for DSM-IV Axis I Disorders (SCIDI) (First et al., 1996). Psychotic symptoms were evaluated using the five-dimensional model of schizophrenic symptoms (positive, negative, cognitive, excitement, and depression/anxiety factors) of the Positive and Negative Syndrome Scale or PANSS (Fresán et al., 2005; Lindenmayer et al., 1995). We used the Calgary Depression Scale for Schizophrenia (CDSS) for depressive symptoms (Addington et al., 1992; Ortega-Soto et al., 1994), and we excluded all patients with Calgary scale outcome $\geq 6$ points.

2.3 Assessment procedures in siblings group, and control group.

To exclude psychopathology in control subjects and siblings, we used the Symptoms Check List (SCL-90) and SCID-I, we excluded all subjects with high values of psychopathology in SCL-90 scale (Cruz-Fuentes et al., 2005; First et al., 1996). Subjects had no alcohol, no drug abuse (with the exception of nicotine and/or caffeine), and no neurological comorbidities when included. All subjects were evaluated with clinical instruments validated on Mexican populations (Apiquian et al., 2000).

\subsection{Pictures of Facial Affects (POFA)}

We evaluated facial recognition ability in three groups with POFA developed by Paul Ekman. The POFA consists of 110 pictures that contain depictions of the known basic emotions: happiness, sadness, anger, fear, disgust, surprise, and one picture without emotion or neutral (Ekman and Friesen, 1976; Tsoi el al., 2007). These pictures showed in black/white, and subject's choice the correct emotion for there. The hemisphere-laterality in the subjects weren't influence to recognize basic emotions.

\subsection{Statistical analyses}

The description of the clinical characteristics of the patients was performed using frequencies and percentages for categorical variables and means and standard deviations ( $\underline{\text { S.D. }}$ ) for continuous variables. 
Chi square tests (x2) and ANOVAs' were used for the comparison of the demographic characteristics and emotional face recognition ability. For continuous variables, Bonferroni correction was used when a significant difference emerged between groups in the ANOVA test.

For the present analyses, all POFA pictures corresponding to the correct classification were excluded and only the mistaken ones were considered. The percentage of error was calculated according to the total number of mistaken pictures reported in each group.

\subsection{Demographic data}

The patients and controls groups were both paired by gender and age: 21 males (61.8\%) and 13 females (38.2\%). The mean age in the studied population for schizophrenic patients and control subjects was $32.9 \pm 9.8$ yr. For the sibling group, there were 19 males (55.9\%), and 15 females (44.1\%); the mean age in siblings was $33.4 \pm 11.0 \mathrm{yr}$.

We also found differences in the marital status: there were $91.2 \%(n=31)$ schizophrenic patients without partners in contrast with the sibling group, 41.2\% ( $\mathrm{n}=14, \mathrm{p}<0.001)$, and the control group 20.6\% $(\mathrm{n}=7$, $\mathrm{p}<0.001)$. Between siblings and controls, there were no differences $(\mathrm{p}=0.06)$. Regarding occupation, physical activity, and eating habits, we did not find differences, see Table 1.

Table 1. Demographic data

\begin{tabular}{|c|c|c|c|c|c|c|c|}
\hline & \multicolumn{2}{|c|}{$\begin{array}{c}\text { Patients } \\
(\mathrm{n}=34)\end{array}$} & \multicolumn{2}{|c|}{$\begin{array}{c}\text { Siblings } \\
(\mathrm{n}=34)\end{array}$} & \multicolumn{2}{|c|}{$\begin{array}{c}\text { Controls } \\
(\mathrm{n}=34)\end{array}$} & \multirow[t]{2}{*}{ Statistics } \\
\hline & $\mathrm{n}$ & $\%$ & $\mathrm{n}$ & $\%$ & $\mathrm{n}$ & $\%$ & \\
\hline \multicolumn{8}{|l|}{ Gender } \\
\hline Male & 21 & 61.8 & 19 & 55.9 & 21 & 61.8 & \multirow{2}{*}{$\mathrm{x}^{2}=0.3,2 \mathrm{gl}, \mathrm{p}=0.84$} \\
\hline Female & 13 & 38.2 & 15 & 44.1 & 13 & 38.2 & \\
\hline \multicolumn{8}{|l|}{ Marital Status } \\
\hline Without partner & 31 & 91.2 & 14 & 41.2 & 7 & 20.6 & \multirow[t]{2}{*}{$\mathrm{x}^{2}=35.8,2 \mathrm{gl}, \mathrm{p}<0.001$} \\
\hline With partner & 3 & 8.8 & 20 & 58.8 & 27 & 79.4 & \\
\hline \multicolumn{8}{|l|}{ Occupation } \\
\hline Without work & 19 & 55.9 & 14 & 41.2 & 14 & 41.2 & \multirow{2}{*}{$\mathrm{x}^{2}=1.9,2 \mathrm{gl}, \mathrm{p}=0.37$} \\
\hline With work & 15 & 44.1 & 20 & 58.8 & 20 & 58.8 & \\
\hline \multicolumn{8}{|l|}{ Physical activity } \\
\hline Low & 21 & 61.8 & 17 & 50.0 & 14 & 41.2 & \multirow{3}{*}{$\mathrm{x}^{2}=4.1,4 \mathrm{gl}, \mathrm{p}=0.38$} \\
\hline Middle & 10 & 29.4 & 12 & 35.3 & 17 & 50.0 & \\
\hline High & 3 & 8.8 & 5 & 14.7 & 3 & 8.8 & \\
\hline \multirow{5}{*}{$\begin{array}{l}\text { Alimentation } \\
\text { Low calories } \\
\text { Balanced } \\
\text { High calories }\end{array}$} & \multirow{2}{*}{\multicolumn{2}{|c|}{0}} & & \multirow{2}{*}{\multicolumn{2}{|c|}{0}} & \multirow{4}{*}{$\mathrm{x}^{2}=8.4,6 \mathrm{gl}, \mathrm{p}=0.20$} \\
\hline & & & 3 & 8.9 & & & \\
\hline & \multicolumn{2}{|r|}{64.7} & 18 & 52.9 & 21 & 61.7 & \\
\hline & 12 & 35.3 & 13 & 38.2 & & 38.3 & \\
\hline & \multicolumn{2}{|c|}{ MD SD } & \multicolumn{2}{|c|}{ MD $\quad$ SD } & \multicolumn{2}{|c|}{$\mathrm{MD} \quad \mathrm{SD}$} & \\
\hline Age & \multicolumn{2}{|c|}{$32.9 \pm 9.8$} & \multicolumn{2}{|c|}{$33.4 \pm 11.0$} & \multicolumn{2}{|c|}{$32.9 \pm 9.8$} & $\mathrm{~F}=0.03,2 \mathrm{gl}, \mathrm{p}=0.97$ \\
\hline Schooling & \multicolumn{2}{|c|}{$13.0 \pm 3.0$} & \multicolumn{2}{|c|}{$13.5 \pm 3.4$} & \multicolumn{2}{|c|}{$18.0 \pm 3.0$} & $\mathrm{~F}=26.61,2 \mathrm{gl}, \mathrm{p}<0.001$ \\
\hline
\end{tabular}

$\mathrm{n}=$ Number of participants, $\mathrm{MD}=$ Mean Difference, $\mathrm{SD}=$ Standard deviation. 
Control subjects had a high school education level, the mean age was $18 \pm 3.0 \mathrm{yr}$. in contrast with patients $13.0 \pm 3$ yr. and the patients' siblings $13.5 \pm 3.4$ yr.; these differences were statistically significant with $p<0.001$.

\section{Results}

\subsection{Schizophrenic patients, clinical data}

Among the studied group, the most common subtype of schizophrenia was paranoid schizophrenia (32 out of 34 patients), one patient had disorganized schizophrenia, and one patient had undifferentiated subtype of schizophrenia (used DSM-IV-TR criteria). The mean onset age of the illness was at $23.06 \pm 7.9 \mathrm{yr}$. (age range 1352 yr.). Untreated psychosis duration was 98.6 \pm 157.0 weeks (range 1-626 weeks). The diagnoses were established around 25 years of age, MD 25.0 \pm 7.9 (range 16-52 years). The $64.7 \%$ of patients had a history of hospitalizations with a mean of 2.27 times, for $24.5 \pm 48.0$ weeks. The severity of the disease in the patients was evaluated with the PANSS scale, and evaluated depression symptoms with Calgary scale (table 2). All patients were taking antipsychotics medication, $91.2 \%$ of the patients were taking second generation antipsychotics (see table 3).

Table 2. Schizophrenic patients, clinical data.

\begin{tabular}{|l|c|}
\hline Clinical Scales & MD \\
\hline PANSS & $22.1 \pm 4.4$ \\
Positive symptoms & $23.4 \pm 3.9$ \\
Negative symptoms & $21.3 \pm 2.9$ \\
Cognitive symptoms & $4.4 \pm 1.2$ \\
Excitability symptoms & $5.4 \pm 2.1$ \\
\multicolumn{1}{c|}{ Depression / Anxiety } & $76.5 \pm 9.0$ \\
Total score Depression Scale for & $1.2 \pm 1.3$ \\
\hline $\begin{array}{l}\text { The Calgary } \\
\text { schizophrenia (CDS) }\end{array}$ & \\
\hline
\end{tabular}

$\mathrm{MD}=$ Mean Difference, $\mathrm{SD}=$ Standard deviation

\subsection{Facial recognition of emotions}

We recorded the percentage of emotional face recognition in each of the groups. In all groups, patient group, siblings, and control subjects, the least recognized emotion was fear (56.6\%). Surprise was the most recognized emotion within the patient group (89.7\%) and within the sibling group (92.2\%). The control group acknowledged more the neutral emotion face with the highest percentage of them all $(98.7 \%)$. The post hoc 
analysis conducted on facial recognition of emotions revealed that differences found among the groups were found between the patient group and the control group and they were related to the recognition of happiness $(p=0.008)$, sadness $(p=0.002)$, anger $(p=0.001)$, surprise $(p=0.03)$, fear $(p=<0.001)$, disgust $(p=<0.001)$ and neutral emotion $(p=0.01)$, while the sibling group remained at an intermediate level, without differences between the patient group or the control group regarding the recognition of these emotions $(p>0.05)$, with the exception for fear and disgust. Control subjects had a higher recognition of fear when compared to the patients group ( $p<0.001)$ and the siblings group $(p=0.02)$, with no differences between the recognition of fear among patients and their siblings $(p=0.68)$. The same result was observed in the recognition of disgust, which was higher in the control group in contrast to patients group $(p<0.001)$ and siblings group $(p=0.01)$, with no recognition of this emotion differing between these two groups $(p=0.15)$.

Table 3. Antipsychotics treatment.

\begin{tabular}{|l|cc|cc|}
\hline \multicolumn{1}{|c|}{ Antipsychotics } & n & \% & \multicolumn{2}{|c|}{ Doses mg } \\
& & & MD & SD \\
\hline Olanzapine & 10 & $(29.4)$ & 10 & $(5-15)$ \\
Risperidone & 9 & $(26.5)$ & 4 & $(2-6)$ \\
Clozapine & 6 & $(17.6)$ & 400 & $(200-600)$ \\
Quetiapine & 3 & $(8.8)$ & 600 & $(450-900)$ \\
Sulpiride & 3 & $(8.8)$ & 400 & $(200-600)$ \\
Amisulpride & 1 & $(2.9)$ & 300 & $(200-400)$ \\
Ziprasidone & 1 & $(2.9)$ & 120 & $(80-160)$ \\
Aripiprazole & 1 & $(2.9)$ & 15 & $(10-20)$ \\
\hline
\end{tabular}

\subsection{Mistaken in facial recognition of emotions}

Happiness was mistaken for neutral face by $13.0 \%$ of the patients, $8.4 \%$ of the siblings, and $7.7 \%$ in the control group, there aren't differences between groups ( $\mathrm{x} 2=8.97, \mathrm{p}=0.53)$ (see graph 1 ). 
Graph 1. Mistakes in recognition of happiness.

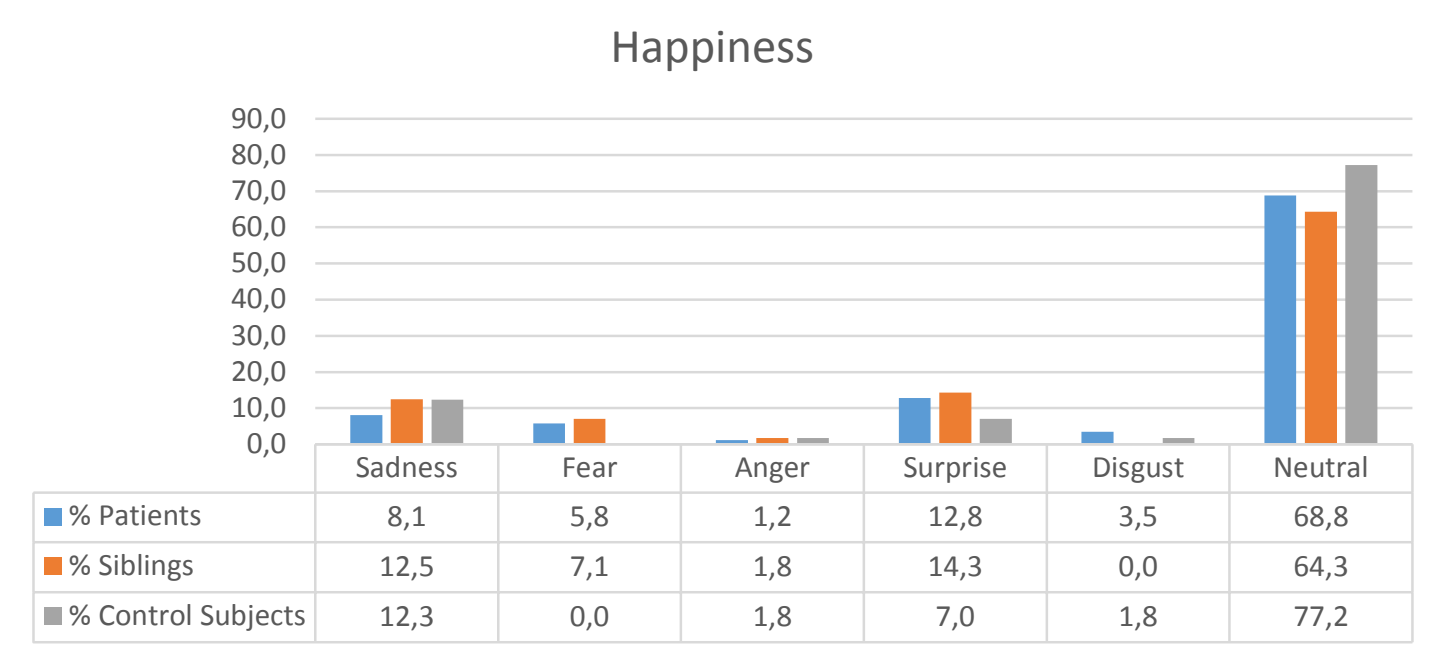

The pictures of anger were the ones with more variability in terms of assigned emotion, but the difference between groups do not reach statistical significance. Only patients confused anger with neutral emotion while siblings were the only that confuse this emotion with sadness $(x 2=18.2, p=0.05)$.

Surprise: misattribution was lower in all of the groups. The patients group were mistook surprise for disgust in $2.1 \%$ (for happiness in $1.3 \%$, and for fear in $1.3 \%$ ), siblings group were changed surprise for fear in $2.1 \%$, and control subjects were mistook for neutral faces in $1.0 \%$.

Neutral face: the patient group mistook the neutral face for sadness in $4.6 \%$, and for happiness in $2.1 \%$, the siblings group mistook for sadness in $2.0 \%$, and for happiness in $2.1 \%$, the control group recognized neutral face in $98.7 \%(x 2=5.01, p=0.89)$.

Sadness was primarily recognized as fear in the three groups; nevertheless, a higher percentage of siblings confused sadness with anger, while more pictures of sadness were mistaken as neutral emotion by patients and control subjects $(\mathrm{x} 2=32.2, \mathrm{p}<0.001)$ (see graph 2$)$.

Graph 2, Mistakes in recognition of sadness.

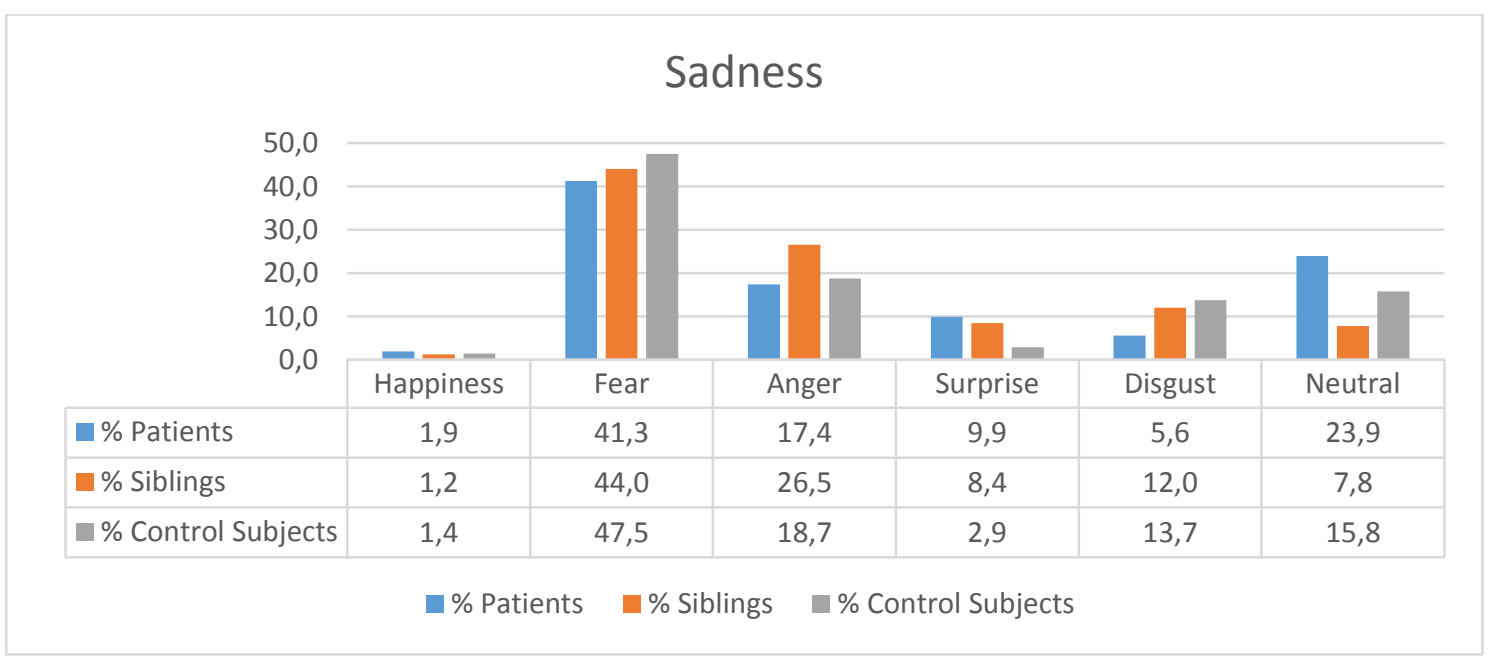


Fear was the least recognized emotion. The patient group mistook it for surprise $42.6 \%$ and anger $6.9 \%$. The siblings mistook it for surprise $41.3 \%$, and the control group also for surprise $25.4 \%$ (see graph 3 ).

Although the majority of the pictures of disgust were confused with anger in the three groups a higher percentage of patients and siblings confused this emotion with other ones, including happiness and surprise $(\mathrm{x} 2=22.4, \mathrm{p}=0.01)($ see graph 4$)$.

Graph 3, Mistakes in recognition of fear.

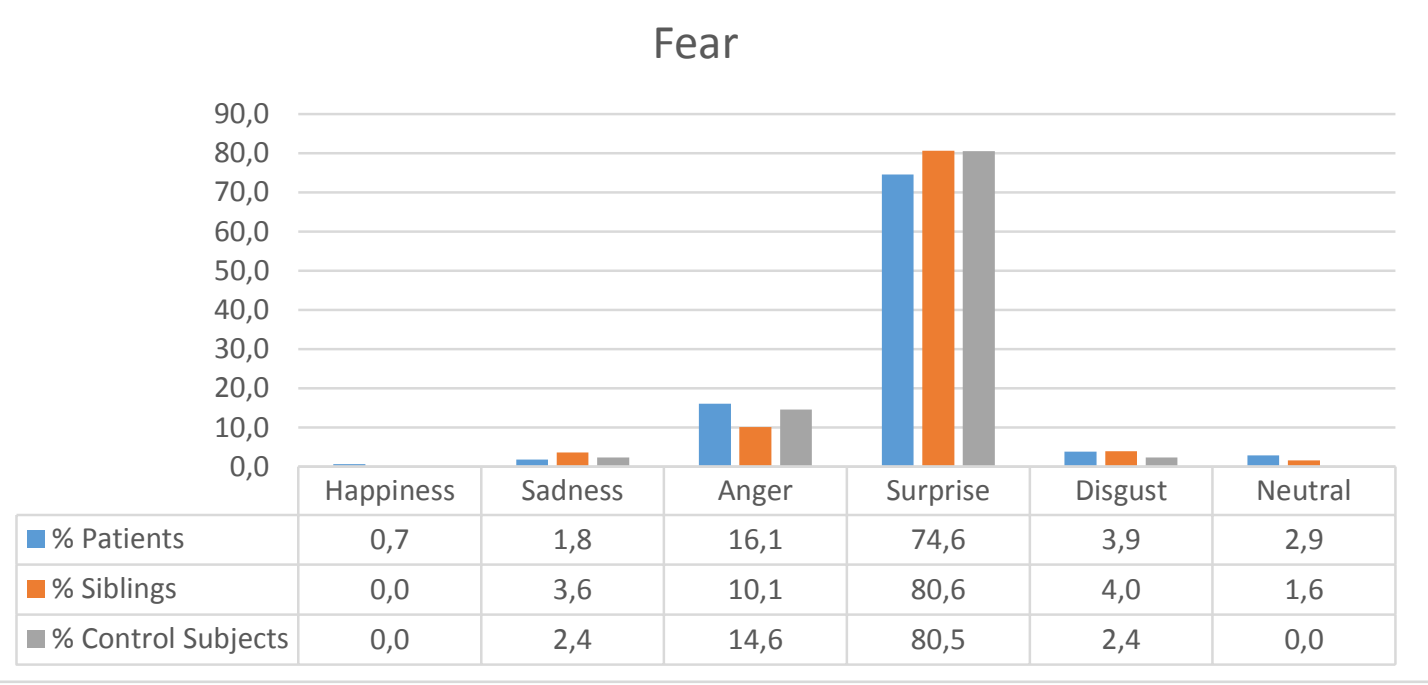

Graph 4, Mistakes in recognition of disgust.

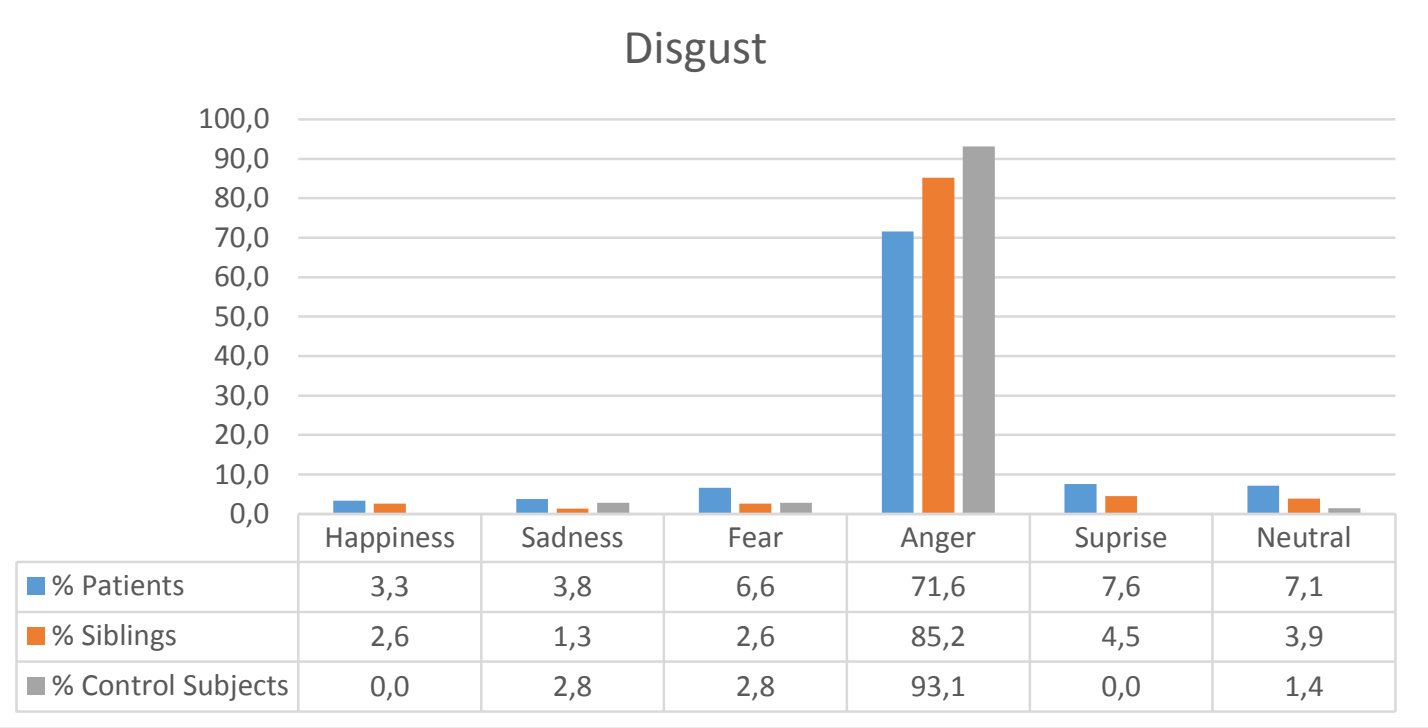




\section{Discussion}

When analyzing emotion facial recognition, differences were found among the three groups in recognizing fear and disgust. Control subjects had a higher recognition of fear compared to the patient group and the sibling group, with no differences between the recognition of fear between patients and their siblings. The differences in the recognition of fear on previous studies reported a poor recognition of fear; these findings have also been described in different ethnic groups and in different populations (Pinkham et al., 2008; Mendoza et al., 2011).

In our study, we found a lot of changes in the correct recognition of an emotion in all groups, but the patient group was the worst in recognizing emotions, especially negative emotions. The deficit in recognizing fear, disgust, and sadness has been associated with the decreased ability of processing information in the social context and beyond (Dougherty et al., 1974; Muzekari and Bates, 1977; Kerr and Neale, 1993; Salem et al., 1996). Also, this phenomenon has been linked to increased punitive behaviors such as higher mistrust and less interpersonal cooperation in family activities in subjects with schizophrenia (Mendoza, et al., 2011; Trémeau et al., 2009; Kohler et al., 2010; Tse et al., 2011).

After fear, disgust was the less recognized emotion among the three groups, the sibling group also had a lower recognition of the same emotions being positioned in the middle. These outcomes could confirm the cognitive failure in patients and siblings, which has been reported in literature, since the deficit of fear recognition is associated with a decreased ability of processing information in the social context (Mendoza et al., 2011; Hall et al., 2004; Bediou et al., 2007). This has been associated with a lower ability to identify external stimuli. Misidentification of these has been related to the degree and the intensity of paranoid thoughts. (Susskind et al., 2008; Thewissen et al., 2011). The deficits in facial recognition in negative emotions, mainly a low recognition of fear and disgust, appear in the first episode of psychosis (Tsoi et al., 2008).

In contrast, the best recognized emotion by patients and siblings was surprise, and in control subjects it was neutral. These results were different from other trial results in which the authors found a higher recognition of happiness and neutral emotion (Gard et al., 2011). Positive emotions are associated with the ability of maintaining relationships, general performance, and motivational behaviors in healthy people, situation which does not occur in schizophrenia, which seems to dominate the misidentification of emotions, as observed by Strauss and Herbener (2011). The schizophrenic patients had lower scores in facial recognition, they also had lower social abilities, and a significant proportion of behavioral problems when they were exposed to social scenarios and interactions (Hooker et al., 2002). This supports the presence of basic cognitive failures in patients and their siblings, which has been reported in the literature before (Mandal and Palchoudhury, 1985; Chung and Barch, 2011; Lee et al., 2010; Tse et al., 2011).

\section{CONCLUSIONS}

These outcomes are present in all groups, the worst group to recognition emotion were the patients group, and the best recognition emotion groups were the control subjects. The siblings group also had a lower recognition of the same emotions being the latter positioned in the middle, between patients and controls.

Our results suggest the presence of widespread deficits in patients with schizophrenia and their siblings, which may be a heritable endophenotype in schizophrenia, since the phenomenon appears to behave as such. These endophenotypes correspond to the changes seen in patients, relatives, and controls, which together show the pathophysiological processes underlying the disease. 
In clinical conclusions, we thought that the different mistaken in groups could be reinforcement the delusions or over interpreted the social context in patients and siblings group, like a part of phenomenon in social cognition marked to differences in patients, non-patients but high risk to development psychosis and control subjects.

\section{Bibliography and references.}

ADDINGTON, D. ADDINGTON, J. MATICKA-TYNDALE, E. Reliability and validity of a depression rating scale for schizophrenics. Schizophr Res, 1992, vol. 6 no. 3, p. 201-208.

AMERICAN PSYCHIATRIC ASSOCIATION. Diagnostic and Statistical Manual of Mental Disorders. American Psychiatry Association Press, 1994, Fourth ed. USA.

APIQUIÁN, R. FRESÁN, A. NICOLINI, H. Evaluación de la Psicopatología. Escalas en español. Editorial Ciencia y Cultura Latinoamericana S.A. de C.V, 2000, First ed. Mexico.

BEDIOU, B. ASRI, F. BRUNELIN, J. KROLAK-SALMON, P. D'AMATO, T. SAOUD, M. TAZI, I. Emotion recognition and genetic vulnerability to schizophrenia. BrJ Psychiatry, 2007, vol. 191, p. 126-30.

BREKKE, J. NAKAGAMI, E. KEE, K. GREEN, M. Cross-ethnic differences in perception of emotion in schizophrenia. Schizophr Res, 2005, vol. 15, no. 77 (2-3), P. 289-298.

CACIOPPO, J. BERNTSON, G. SHERIDAN, J. McCLINTOCK, M. Multilevel integrative analyses of human behavior: Social neuroscience and the complementing nature of social and biological approaches. Psychol Bull, 2000, vol. 126, no. 6, p. 829-843.

CAMCHONG, J. MACDONALD III, A. BELL, C. MUELLER, B. LIM, K. Altered functional and anatomical connectivity in schizophrenia. Schizophr Bull, 2011, vol. 37, no. 3, p. 640-650.

CAMCHONG, J. LIM, K. SPONHEIM, S. MACDONALD III, A. Frontal white matter integrity as an endophenotype for schizophrenia: diffusion tensor imaging in monozygotic twins and patients' nonpsychotic relatives. Front Hum Neurosci. 2009 Oct 26;3:35. doi: 10.3389/neuro.09.035.200

CHUNG, Y. BARCH, D. The effect of emotional context on facial emotion ratings in schizophrenia. Schizophr Res, 2011, vol. 131, no. 1-3, p. 235-241.

CRUZ-FUENTES, C. LÓPEZ-BELLO, L. BLAS-GARCÍA, C. GONZÁLEZ-MACÍAS, L. CHÁVEZ-BALDERAS, R. Datos sobre la validez y confiabilidad de la Symptom Check List 90 (SCL 90) en una muestra de sujetos mexicanos. Salud Mental, 2005, vol. 28, p. 72-81.

DOUGHERTY, F. BARTLETT, E. IZARD, C. Responses of schizophrenics to expressions of the fundamental emotions. J Clin Psychol, 1974, vol. 30, no. 3, p. 243-6.

ELFENBEIN, H. AMBADY, N. On the universality and cultural specificity of emotion recognition: a meta-analysis. Psychol Bull, 2002, vol. 128, no. 2, p. 203-235.

EKMAN, P. Strong Evidence for universals in facial expressions: A reply to Russell's mistaken critique. Psychol Bull, 1994, vol. 115, p. 268-287.

EKMAN, P. FRIESEN, W. Pictures of facial affect. Human Interaction Laboratory, University of California Medical Center, 1976, first ed. USA.

FIRST, M. SPITZER, R. GIBBON, M. WILLIAMS, J. Structured Clinical Interview for DSM-IV Axis I Disorders (SCIDI), Clinician Version. American Psychiatric Press, 1996, first ed. USA.

FRESÁN, A. DE LA FUENTE-SANDOVAL, C. LÓYZAGA, C. A forced five-dimensional factor analysis and concurrent validity of the positive and negative syndrome scale in Mexican schizophrenic patients. Schizophr Res, 2005, vol. 72, p. 123-129.

GARD, D. COOPER, S. FISHER, M. GENEVSKY, A. MIKELS, J. VINOGRADOV, S. Evidence for an emotion maintenance deficits in schizophrenia. Psychiatry Res, 2011, vol. 187, no. 1-2, p. 24-9. 
GOTTESMAN, II. GOULD, T. The endophenotype concept in psychiatry: etymology and strategic intentions. $A m \mathrm{~J}$ Psychiatry, 2003, vol. 160, no. 4, p. 636-645.

GREENWOOD, T. BRAFF, D. LIGHT, G. CADENHEAD, K. CALKINS, M. DOBIE, D. FREEDMAN, R. GREEN, M. GUR, R. GUR, R. MINTZ, J. NUECHTERLEIN, K. OLINCY, A. RADANT, A. SEIDMAN, L. SIEVER, L. SILVERMAN, J. STONE, W. SWERDLOW, N. TSUANG, D. TSUANG, M. TURETSKY, B. SCHORK, N. Initial Heredability Analyses of Endophenotypic measures for schizophrenia. The consortium on the genetics of schizophrenia. Arch Gen Psychiatry, 2007, vol. 64, no. 11, p. 1242-1250.

HALL, J. HARRIS, J. SPRENGELMEYER, R. Social Cognition and face processing in schizophrenia. Br J Psychiatry, 2004, vol. 85, p. 169-170.

HOOKER, C. PARK, S. Emotion processing and its relationsship to social functioning in schizophrenia patients. Psychiatry Res, 2002, vol. 112, p. 41-50.

IBAÑEZ, A. RIVEROS, R. HURTADO, E. GLEICHGERRCHT, E. URQUINA, H. HERRERA, E. AMORUSO, L, REYES, M. MANES, F. The face and its emotions: Right N170 deficits in structural processing and early emotional discrimination in schizophrenics patients and relatives. Psychiatry Res, 2012, vol. 195, no. 1-2, p. 18-26.

KERR, S. NEALE, J. Emotion perception in schizophrenia: specific deficit or further evidence of generalized poor performance? J Abnorm Psychol, 1993, vol. 102, p. 312-318.

KESHAVAN, M. PRASAD, K. PEARLSON, G. Are brain structural abnormalities useful as endophenotypes in schizophrenia? Int Rev Psychiatry, 2007, vol. 19, no. 4, p. 397-406.

KOHLER, C. WALKER, J. MARTIN, E. HEALEY, K. MOBERG, P. Facial Emotion Perception in Schizophrenia: A Meta-analytic review. Schizophr Bull, 2010, vol. 36, no. 5, p. 1009-1019.

LEE, S. LEE, H. KWEON, Y. LEE, C. LEE, K. Deficits in facial emotion recognition in schizophrenia: a replication study with Korean subjects. Psychiatry Investig, 2010, vol. 7, no. 4, p. 291-7.

LINDENMAYER, J. GROCHOWSKI, S. HYMAN, R. Five factor model of schizophrenia: replication across samples. Schizophr Res, 1995, vol. 14, no. 3, p. 229-34.

MANDAL, M. PALCHOUDHURY, S. Decoding of facial affect in schizophrenia. Psychol Rep, 1985, vol. 56, no. 2, p. 651-652.

MENDOZA, R. CABRAL-CALDERIN, Y. DOMÍNGUEZ, M. GARCIA, A. BORREGO, M. CABALLERO, A. GUERRA, S. REYES, M. Impairment of emotional expression recognition in schizophrenia: a Cuban familial association study. Psychiatry Res, 2011, vol. 185, no. 1-2, p. 44-48.

MUZEKARI, L. BATES, M. Judgment of emotion among chronic schizophrenics. J Clin Psychol, 1977, vol. 33, no. 3, p. 662-666.

ORTEGA-SOTO, H. GRACIA, P. IMAZ, B. Validez y reproductibilidad e una escala para evaluar la depresión en pacientes esquizofrénicos. Salud Mental, 1994, vol. 17, no. 3, p. 7 - 14.

PINKHAM, A. SASSON, N. CALKINS, M. The other-race effect in face processing among African-American and Caucasian individuals with schizophrenia. Am J Psychiatry, 2008, vol. 165, p. 639-645.

RUSSELL, J. Is there universal recognition of emotion from facial expression? A review of cross-cultural studies. Psychological Bull, 1994, vol. 115, p. 102-141.

SALEM, J. KRING, A. KERR, S. More evidence for generalized poor performance in facial perception in schizophrenia. J Abnorm Psychol, 1996, vol. 105, no. 3, p. 480-3.

STRAUSS, G. HERBENER, E. Patterns of emotional experience in schizophrenia: differences in emotional response to visual stimuli are associated with clinical presentations and funtional outcome. Schizophr Res, 2011, vol. 128, no. 1, p. 117-123.

SUSSKIND, J. LEE, D. FEIMAN, R. GRABSKI, W. ANDERSON, A. Expressing fear enhances sensory acquisition. Nature Neurosc, 2008, vol. 11, no. 7, p. 843-850. 
THEWISSEN, V. BENTALL, R. OORSCHOT, M. CAMPO, J. VAN LIEROP, T. VAN OS, J. MYIN-GERMEYS, I. Emotions, self-esteen, and paranoid episodios: an experience sampling study. Bj Clin Psychol, 2011, vol. 50, no. 2, p. 178-195.

TRÉmEAU, F. ANTONIUS, D. GOGGIN, M. CZOBOR, P. BUTLER, P. MALASPINA, D. GORMAN, J. Emotion antecedents in schizophrenia. Psychiatry Res, 2009, vol. 169, no. 1, p. 43-50.

TSE, W. YAN, L. BOND, A. CHAN, R. TAM, D. Facial emotion linked cooperation in patients with paranoid schizophrenia: a test on the interpersonal communication model. Int J Soc Psychiatry, 2011, vol. 57, no. 5, p. 509-517.

TSOI, T. LEE, K. KHOKHAR, W. MIR, N. SWALLI, J. GEE, K. PLUCK, G. WOODRUFF, P. Is facial emotion recognition impairment in schizophrenia identical for different emotions? A signal detection analysis. Schizophr Res, 2008, vol. 99, Issue 1-2, p. 263-269.

Served on the editorial board of 15. 6.2014

Taken after review of 8. 9. 2014 